\title{
Comparative process tracing in housing studies
}

\author{
Bo Bengtsson \\ Institute for Housing and Urban Research \\ Uppsala University \\ Sweden \\ Email: bo.bengtsson@ibf.uu.se
}

\author{
Hannu Ruonavaara \\ Department of Social Research \\ University of Turku \\ Finland \\ Email: hanruona@utu.fi
}

\begin{abstract}
$\underline{\text { Abstract }}$
Comparative social and political research often contains a historical dimension. Lately it has become fashionable to refer to this dimension with the term path dependence. In this paper we propose an approach to comparative housing research that takes the path dependence of social and political processes seriously. In contrast to the traditional understanding of historical research this approach, which can be called comparative process tracing, is quite strongly theoretically informed.
\end{abstract}

We see comparative process tracing as an analysis in two steps. In the first step the goal is to reconstruct as closely as possible a chain of ideal type social mechanisms made portable to other contexts by the assumption of thin rationality. In the second step these processes are compared making use of ideal type periodisation.

We have, together with others, applied comparative process tracing to an analysis of the Nordic housing policies. The paper discusses the basic ideas behind the approach in that research and reflects on how to develop it further. 


\section{Comparative process tracing in housing studies}

\section{Bo Bengtsson and Hannu Ruonavaara}

Comparative social and political research is often understood as moving between the poles of quantitative analysis of large-scale data and intensive, mainly qualitative, comparison of a small number of cases - often states, nations or societies. The latter 'small-n' type of comparison is sometimes carried out in accordance with the idea of 'focused and structured comparison' systematically contrasting a number of central variables derived on the basis of some theory (cf. George and McKeown 1985). Other comparative projects merely consist of a number of national or local studies related to some common theme, often rather generally defined. In housing studies this type of 'unfocused and unstructured comparison' has been aptly labelled 'juxtapositional' (Kemeny and Lowe 1998). However, even the focused and structured variations of variable-oriented comparison between states or other systems often risk running into the well-known problem of too many variables and too few cases.

In this paper we focus on another type of comparison, between historical processes in different, in our case national, settings. This type of longitudinal analysis of chronological sequences has often been described in political science as 'process tracing' (e.g. George and Bennett 2005, chap. 10). Among historical sociologists essentially similar approaches range from more "humanist" analysis of narrative (e.g. Sewell 2005) to more "scientific" sequence analyses (e.g. Abbott 2001). All of these approaches share a focus on temporal change and historical causation detected in the chain of events that produces as its outcome what the research is aiming to interpret and explain.

In the field of housing studies historical perspectives have been applied mainly in rather non-theoretical investigations of single countries or cities - or sometimes parallel historiographic studies of two or more cases. In this paper we propose an approach to comparative housing research that takes the path dependence of social and political processes seriously, thus combining theoretical and chronological elements in order to make some general inference possible. The approach, which can be called comparative process tracing, is influenced by historical institutionalism in political science and comparative historical analysis in sociology. It analyses history, but in contrast to the traditional understanding of historical research, it is quite strongly theoretically informed. We have, together with others, applied comparative process tracing to an analysis of the five Nordic national housing regimes (Bengtsson et al. 2006; cf. Bengtsson and Ruonavaara 2010 for a short presentation in English). This paper will discuss the basic ideas behind the approach chosen in that research and reflect on how it can be developed further.

The purpose of the paper is methodological: to present and discuss the logic behind 'comparative process tracing' as an approach to historical comparison, combining sequential process analysis and counterfactual comparative analysis. This approach will be discussed and evaluated both in general terms and more specifically related to housing studies. We will do that by relating observations and reflections from our empirical study of path dependence in housing policy to relevant theoretical and methodological literature. As often with qualitative approaches there is no clear 
separation between methodology and theory. Thus we cannot discuss our empirical approach without relating it to the theoretical perspective of path dependence. In the conclusions we consider the applicability of our version of comparative process tracing within other theoretical frameworks.

The outline of the paper is as follows. First we present a general actor-based perspective on path dependence, and its relevance to housing policy and provision more specifically. Then we give a brief overview of our comparative study of the Nordic housing regimes, which serves as an illustration to the methodological discussion. In the next part of the paper we outline the two-step logic behind an approach of comparative process tracing. We zoom in on the inherent elements of each one of the two steps and discuss their respective function in the analysis as well as their methodological footing. First we look into the process-oriented step and discuss the two types of elements ('events' and 'mechanisms') of a process of path dependence within a certain country (or other case). Then we discuss the comparative step where we highlight the logic and counterfactual function of the comparison between processes within the context of different systems - in our case between the developments of different housing regimes. Here we focus in particular on the use of periodisation as a tool for comparison.

An important question throughout is whether and how actor-based process tracing may allow for some form of generalisation, and here we propose an approach based on idealtype mechanisms and the assumption of thin rationality.

\section{Path dependence - the strong and weak versions}

The concept and perspective of path dependence has received growing attention in the social sciences in the last decades. Path dependence is often seen as the basic pattern of social and political processes in historical versions of institutional theory (e.g. David 1985, 2007; North 1990; Putnam 1993; Hall and Taylor 1996; Sewell 1996, 2005; Thelen 1999; Mahoney 2000; Pierson 2004). The general idea is that if, at a certain point in time, the historical development takes one direction instead of another, some, otherwise feasible, alternative paths will be closed - or at least difficult to reach - at a later point.

The core of the notion of path dependence is what some consider a truism: history matters. Sewell defines path dependence as a process where 'that what happened at an earlier point in time will affect the outcomes of a sequence of events occurring at a later point in time' (Sewell 1996, 262-263, 2005, 100-101). Some writers find such a broad conception of path dependence unacceptable and suggest narrower definitions (e.g. Mahoney 2000, 507; Pierson 2004, 20-21; David 2007, 120). Mahoney e.g. defines path dependent historical processes as those where contingent events help to produce institutional structures and event sequences with deterministic properties (Mahoney 2000, 507-508). Thus, in Mahoney's perspective the analysis of path dependence means tracing certain historical outcomes back to previous events, which are in themselves contingent and not 'logical consequences' of historical circumstances.

Mahoney's strong definition, however, risks falling into another trap; since deterministic causation can seldom be claimed in the social sciences, the concept would be difficult to apply to an analysis based on social action. A more open definition - 
using Mahoney's own terms - would see path dependence as a historical pattern where one event, which is more or less contingent, considerably changes the probability of subsequent alternative events or outcomes. This 'weak' concept of path dependence would transform the firm demarcation line between contingency and determinacy into a matter of degrees.

In the type of actor based analysis that is characteristic of political and institutional history, the dichotomy between contingency and determinacy is difficult to apply. Actors with intentions can normally be assumed to follow some logic of meaningful action - which may be more or less rational. Without going into the complexities of different theories of action, we venture to say that most students would agree that the behaviour of political actors is to some extent explicable, though seldom in the formal terms of deterministic, probabilistic or contingent. (Such a perspective of contextualised rational action is outlined and applied to housing studies in Somerville and Bengtsson 2002.)

Would weak path dependence mean that we are back to 'history matters'? The answer is yes but, we claim, this does not make the concept empty. Rather the opposite, accepting that history matters in social and economic contexts should entail taking the historical nature of social phenomena seriously and analyse how history matters more precisely in a certain setting. For example to Sewell path dependence is only one element in his quest for an 'eventful' historical sociology (see Sewell 2005).

In this connection we want to highlight three different points. First, the idea of path dependence allows for the possibility that single events, which are not the product of larger social forces or trends, might be influential to societal outcomes. This could even involve some elements of chance. Secondly, previous events might be distant in time from the outcomes that are explained by them. Thirdly, as the process is 'essentially historical', it can only be analysed historically, that is by paying special attention to the temporally ordered sequence of events which leads to the outcome.

In an actor based analysis the typical case of (weak) path dependence is where actors more or less deliberately design institutions at point (or points) A, which at a later point B define the rules of the political game between the same or other actors. In retrospect, the historical development can be perceived as an ongoing and self-reinforcing chain of games between actors, institutional design, new games, new institutions, etc. (cf. Tsebelis 1990 on nested games of institutional design).

One strength of the weak definition is that it does not mark institutional change as being impossible by definition - only as something unexpected that calls for an explanation.

Another strength is that it allows for degrees or modes of path dependence. We suggest as one model, inspired by Steven Lukes' well-known analysis of power, to differentiate between three different 'faces' of path dependence. Earlier, more 'contingent', events at point (or points) A may at point B have an effect on (I) decision-making (were actors choose other alternatives due to what happened at point A), (II) agenda-setting (where other alternatives come up on the political agenda due to what happened at point A) or (III) perceptions (where other alternatives are conceivable to actors due to what happened at point A) (Lukes 2005). As our interest here is in analysis of policy change the three faces of path dependence are framed in terms of conditions of political decision-making. However, they can be generalised to fit also with path dependent 
processes that are not strictly political, like the development of divergent neighbourhood identities (see Robertson et al. 2010). What is at stake here is the influence of history on (a) current choices, (b) the evaluation of what is primary and important in the present situation, and (c) the ways actors see the situation and the options open to them.

\section{Path dependence and housing provision}

Our own definition of path dependence was developed in a recent Nordic project which compared the historical development of the housing regimes of Denmark, Sweden, Norway, Finland and Iceland. In the Nordic project path dependence was defined as '...a historical pattern where a certain outcome can be traced back to a particular set of events on the basis of empirical observation guided by some social theory ${ }^{6}$ (Bengtsson 2008, 5). ${ }^{1}$ Path dependence would then indicate a particular form of analysis that focuses on historical events and specifies in theoretical terms the elements that build up the path between those events. It assumes that history matters - but the empirical challenge is not to 'prove' this general assumption but to identify in what respect and via what type of mechanisms history matters in a certain context.

The general idea that history matters is certainly not new in housing studies. In particular the work by Peter Malpass on the history of British housing provision deserves to be mentioned here (e.g. Malpass 2000, 2005). However, analyses of housing policy framed explicitly in terms of path dependence have so far been rare. This is somewhat surprising; in view of the structural characteristics of housing provision it should be particularly fruitful to analyse housing institutions and policy in those terms.

First, there are the specific features of housing as consumption and investment good. Houses and dwellings last long, they are tied to a specific place, slow to produce, expensive, not easily substituted with other goods etc. (Stahl 1985; Arnott 1987). A housing stock produced over centuries and decades of building activity creates a powerful historical heritage for any government to adjust to when making housing policy decisions. On the 'demand side' the social importance of dwelling, and the emotional, social and cultural 'attachment costs' related to a household's transfer from one dwelling in one housing area to another (Dynarski 1986) also have a stabilising effect. The attachment to a home is, of course, more than attachment to a dwelling, it consists also of attachment to the neighbourhood and the community in which the home exists (cf. Saunders and Williams 1988). Social exclusion and norms of eligibility add to the continuity of the residential structure. All these physical and social elements of sluggishness in the housing market have institutional implications that may serve as obstacles to policy change.

Second, housing policy can be perceived as the state providing correctives to the housing market. Market contracts serve as the main mechanism for distributing housing, while state intervention typically has the form of correctives, defining the economic and institutional setting of those contracts (Bengtsson 2001; cf. Torgersen 1987, 116-118).

\footnotetext{
${ }^{1}$ The results from the study are presented in a co-authored book in Swedish of some 400 pages (Bengtsson et al. 2006; cf. Bengtsson and Ruonavaara 2010 for a short presentation in English). Results from the project on specific countries have been published in English in Annaniassen 2008, Bengtsson 2004 and Ruonavaara 2008a, 2008b.
} 
Hence, the main political institutions of the housing sector are those that define the rules of the game in the market, crucially tenure forms and other types of regulations, including the existence of non-profit organisations in the market. ${ }^{2}$ Housing tenures help define the basic rights of possession and exchange that are fundamental to a capitalist economy, so some political self-restraint may be expected: e.g. avoiding forcing major changes through without the support of a stable parliamentary majority.

Third, the fact that housing is ultimately distributed in the market may in itself serve as a constraint to political change. For a new tenure form to be successful it is not enough that it is supported by politicians and voters; consumers must also be prepared to pay for it in the market - and producers to supply it.

These characteristics would e.g. make it difficult to introduce a new form of tenure, say cooperative housing, which is inexistent or of minor importance in most contemporary housing systems, as a serious alternative, at least in a short time span. Due to the abovementioned material features, years and years of production would not be enough to create a substantial cooperative sector, and transforming e.g. public rental housing into cooperatives would probably cause some concern and dissatisfaction among tenants, not to mention resistance from strong organised interests representing public owners, private builders or residents. Moreover, it is likely that prospective cooperative residents would be rather suspicious of such a new institution - perhaps rightly so, because it would not have been tried in problematic market situations.

In sum, the material, mental and social characteristics of housing as a good tend to create strong elements of inertia that housing policies have to deal with. Taken together, they should indeed make housing policy more path dependent than other policy fields. Nevertheless applications in housing of path dependence analysis have so far been scarce (cf. Bengtsson 2009).

\section{The path dependence of the Nordic housing regimes}

The research project that we use as illustration in this paper took its departure from the remarkable differences between the national systems of housing provision in the Nordic countries. Though housing policy in all five countries has been 'social' in the general meaning that an important goal has been to provide decent housing to households of lesser means, the institutional arrangements chosen to achieve this goal differ fundamentally.

In Denmark social housing policy has been primarily directed towards rental housing, in particular in estates owned and managed by housing associations and organised in small self-governed units where local tenants have a high degree of self-management. In Sweden social housing policy has been implemented primarily by means of rental housing managed by public housing companies, which are owned by the local municipalities. In Norway social housing policy has been mainly based on individual and co-operative ownership, there are few professional landlords, and the public rental

\footnotetext{
${ }^{2}$ Ruonavaara $(2005,214)$ defines housing tenures are 'institutions, sets of practices and rules that regulate a particular field of human action and interaction' Thus political decision-making on housing tenures, including how social housing is organised, sets the rules of housing politics on lower levels - and, through institutionalisation, on the macro level as well.
} 
sector represents only a marginal percentage of the total stock. In Iceland too, owneroccupation has been used as a policy instrument of social housing, though in this case including strong elements of individual self build. In Finland, finally, social housing policy has not been directed at any particular form of tenure. State support, combined with individual means-testing, has been given to both rented housing and owneroccupation. Swedish, Danish and Norwegian housing policies have been described as 'universal' and directed towards all types of households. Finnish and Icelandic housing policies on the other hand are seen as 'selective' and oriented more directly towards households of lesser means and based to a large extent on individual means-testing.

The vast differences between the housing regimes of five countries that share a number of similarities in other respects - cultural, economic and political - is truly a puzzle. We would rather expect some signs of convergence, in particular when we consider the collaboration and exchange of ideas that continuously takes place between Nordic politicians, bureaucrats and interest organisations. But the Nordic countries have retained their divergent housing regimes for at least 60 years by now.

Even though this is a methodological paper a few words should be said about the solution to the puzzle of 'why so different'. Very briefly, in the formative period of the Nordic housing regimes, between the turn of the century 1900 and World War II, different solutions - more or less contingent, to use Mahoney's terms - were chosen in each country in order to deal with specific housing problems that occurred at different points of time. When comprehensive programmes of housing policy were introduced after WWII, it was often seen as efficient (or even taken for granted) that the already existing, if still undeveloped, organisations and institutions should be utilised to implement the new programmes. With the massive production of new housing between 1950 and 1980, the differing housing regimes were successively consolidated and institutionalised.

In all Nordic countries housing provision has gone through structural transformation due to industrialisation, wartime crisis, mass construction, and subsequent market maturation and privatisation. Nevertheless, the early differences have been remarkably persistent through the various challenges; the institutional changes that have taken place in each country have been largely incremental, and the new arrangements have retained distinct features of the preceding ones. This is true even in the few cases where political actors have framed the reforms as 'system shifts'.

So history has indeed mattered. However, in order to define the processes as path dependent, even in our weak sense, we must show that the different outcomes 'can be traced back to a particular set of events on the basis of empirical observation guided by some social theory' (cf. above). We now go on to discuss the methods used to achieve that.

\section{Comparative process tracing - the general logic}

As already indicated the methodological procedure of comparative process tracing consists of two steps, one process-oriented and one comparative. These two steps follow rather different research logics, and are then linked together using ideal-type analysis in a way that will be described below. 
The two steps provide different types of methodological challenges. In the first step the existence and forms of path dependence need to be identified and evidenced convincingly manner as something more precise than 'history matters' and in more general terms than a thick narrative. We will argue that the means to accomplish this is to relate the empirical observations to theory or, more precisely, to ideal-type social mechanisms.

In the second step the challenge is to compare systematically social processes in different settings without having access to variable-based structured and focused comparison - in process studies the number of relevant 'variables' would be practically infinite if such an approach was attempted. We will argue that this challenge can be met by using theory-based ideal-type periodisation as comparative device.

In the following two sections we elaborate and specify the research procedures of these two steps.

Process tracing is often described as an attempt to identify the intervening causal process between an independent variable and the outcome of a dependent variable (e.g. George and Bennett 2005, 206). However, we find it somewhat farfetched - or at least awkward - to define the events at points $\mathrm{A}$ and $\mathrm{B}$ in a path dependence analysis (or other historical accounts) as variables, since it is normally neither fruitful nor possible to describe them in the language of variable analysis, nor to define the possible 'variation'.

\section{Tracing path dependence - critical junctures and political focal points}

Briefly put the purpose of a path dependence analysis of an historical process is to identify two types of elements, events and mechanisms. When it comes to events the path dependence literature tends to concentrate on so-called critical junctures (Collier and Collier 1991; Hall and Taylor 1996; Mahoney 2000), i.e. events or points in time where a certain historical path is 'chosen' - more or less intentionally or consciously. A critical juncture represents a point in time where, for some reason, an old path is abandoned and a new path entered upon. In order to be able to say more than just history matters, the challenge is to find an explanation both of the change taking place at the critical juncture and the stability of the new path. And this explanation should preferably be expressed in theoretical terms.

Critical junctures are often associated with sudden crisis and dramatic change. But historical experience has taught us that sometimes events that were not seen as crucial when they occurred have changed the world in the long run. In the housing history of the Nordic countries we found numerous examples of how apparently modest decisions and measures had far-reaching implications that were not realised by actors at the time, but only in historical hindsight.

One illuminating example of this is the birth of the unparalleled Swedish system of collective and 'corporatist' rent negotiations between organisations representing the public and private landlords and the uniquely strong and centralised tenant unions. In the years of the First World War, when economic crisis had led to serious housing 
shortage, dramatic rent increases and outright poverty, the municipalities were granted the right to set up special units with the task to mediate in rental conflicts between landlords and tenants. Those 'rent tribunals' were to include one member 'well versed in housing production' and one 'with knowledge about the housing conditions of people of small means'.

Though these rent tribunals had very limited influence, and tenants' associations were barely existent at the time, this optional institution meant the start of corporatist representation in the Swedish rental sector. When, for similar reasons, a new control system was introduced during WWII, 'corporatist' rent tribunals were again part of the system, this time with much stronger influence on the rent-setting. At this critical juncture the decision was taken without any debate whatsoever in the Parliament. When the rent control was finally abolished some 30 years later the tenant movement had achieved enough power to get the rent tribunals replaced by the system of collective bargaining, which dominates the Swedish rental market still today (Bengtsson 2004).

The sometimes modest outward appearance of critical junctures means that they are not always easy to identify, not even in historical hindsight. To be able to do that it is often necessary to analyse another type of events, which in the Nordic project were labelled political focal points (cf. Schelling 1980, who, however, uses the term 'focal point' with a somewhat different meaning). In our case this would typically be an important political decision process, somehow related to the basic elements of the housing regime. In the project obvious candidates as focal points, besides major reforms of the housing systems, were political decisions on tenure legislation, organisation and ownership, or on subsidies directed towards specific tenures. From a methodological point of view these political events are where we would expect path dependence to be visible: in the contents of the decisions, in the political debates about them, and in the general discourse.

It should be underlined that sometimes a political focal point may at the same time actually be a critical juncture. Such 'focal critical junctures' have been labelled formative moments (Rothstein 1998). In housing policy they may often rather be drawnout 'formative periods' - where actors intentionally and over some time try to induce historical change. In the historical paths of the Nordic housing regimes the years immediately after WWII represent such a formative period in all countries - including both critical junctures and political focal points.

Our main point here is, however, that the two types of events do not always coincide. Critical junctures sometimes lack all dramatic qualities, whereas more visible focal points often just consolidate prevailing institutions. The methodological implication is that in order to find the critical juncture A one should start the investigation at focal point $\mathrm{B}$. If we find at B that some, otherwise plausible, paths are seen as closed by the involved actors - or not even considered - this would be an indication of how to find point A, by going backwards in history to the situation where closure took place. Point $\mathrm{B}$ is almost by definition easy to locate, while the event at point A may not have been much debated, or even observed, at the time. ${ }^{3}$

\footnotetext{
${ }^{3}$ The history of the Swedish corporatist rental sector summarised above is one example of point A not being very evident. A drastic example of point B not necessarily bringing about dramatic change is the fact that the Francoist system of 'protected housing' based on social categorization and zoning of the city
} 
One interesting methodological complication with the approach should be mentioned. If there is indeed path dependence, the alternatives that were closed at the critical juncture A may not even be visible when we investigate the political focal point $\mathrm{B}$. Referring to Lukes, if it is not a case of 'decision-making' path dependence, but of the 'agendasetting' or even 'perceptual' variations, we may not find any trace of the deserted path when studying the decision-making process at point B. Sometimes alternatives seen as unrealistic by actors may be commented on but, if not, such forms of path dependence must be spotted by other means.

\section{Tracing path dependence - social mechanisms}

This takes us from events to mechanisms. The social mechanisms of path dependence are what link the chain of critical junctures and political focal points together, and this is where theory comes in. As a starting-point to our discussion of these mechanisms, we again contrast our actor-based perspective to Mahoney's position.

Inspired by Randall Collins, Mahoney presents a typology of path-dependent explanations of institutional reproduction, making a distinction between utilitarian, functional, power and legitimation explanations. In utilitarian explanation the mechanism is the rational cost-benefit assessment of the institution by actors, and in functional explanation it is the function of the institution for an overall system. In legitimation explanation the mechanism at work is the belief of actors in the morality or appropriateness of the institution, and in power explanation it is the support by an elite group of actors. Depending on the mechanism, the effect of the (contingent) event that occurred at point A would be that at point B some now less efficient, less functional, less legitimate or less strongly supported solutions would not be available (Mahoney 2000, 517-524).

Mahoney's typology mixes rational choice, functionalism, idealism and power analysis. His alternative explanations actually imply a choice between theoretical perspectives, and it is difficult to conceive of an analytical framework that could integrate - or even be neutral between - his four explanations in an empirical analysis.

In an actor based analysis the point of departure should in principle be subjective and based on (1) how the actors conceive of the situation at point B, (2) what alternatives enter into their 'calculi' (which may be more or less explicit or sophisticated), and (3) how they interact with other actors in the decision-making (or nondecision-making) process. This means that Mahoney's utilitarian mechanism is the core of the analysis, even though it should often be defined in less perfectly rationalistic terms than Mahoney seems to imply. However, Mahoney's utilitarian mechanism conflates utility and economy. In a perspective of contextualised rational action not only economic values but e.g. legitimacy and power can enter the calculus of an actor.

Several writers in the path dependence tradition point out the efficiency mechanism which has to do with the coordinating capacity of established institutions and with the transactions costs of changing them (e.g. North 1990; Hall and Taylor 1996, 945; 
Pierson 2000). The legitimacy mechanism can work as a determinant either of actors' own preference orders or more indirectly via their perception of what is seen as legitimate in the society at large. Correspondingly the power mechanism may work both directly and indirectly; directly in deciding which actors are allowed to take part in a decision and their respective influence on the outcome; or indirectly via actors' perception of power relations in the larger society (cf. Thelen 1999, 394-396). ${ }^{4}$

One type of path dependence which is of particular relevance to housing has to do with the physical sluggishness of buildings and neighbourhoods discussed above. Even though this sluggishness is physical and technical, it has institutional implications by placing definite restraints on decision-making about housing provision at a later point $\mathrm{B}$. This can either be seen as a very strong version of the economic mechanism or as a specific 'technical' variation (cf. Hughes 1983).

This discussion has certain implications for the role of theory in the analysis of path dependence. In Mahoney's model theory is needed to decide what events at point A are contingent or not. In a perspective of contextualised rational action the role of theory is twofold: first to make sense of actors and decision-making at points $\mathrm{A}$ and $\mathrm{B}$, and second to help explain more precisely the mechanisms at work along the path, i.e. what aspects of the event A, or its effects, defines the rules of the game and the actors' preferences at point B. Unlike Mahoney's strong version of path dependence, where a move from the contingent to the deterministic calls for an explanation in terms of one inclusive mechanism, our weak actor oriented version allows for a combination of different mechanisms explaining actors' perception of the situation at point B.

Hence, in an actor-based historical analysis the typical case of path dependence is where actors more or less deliberately design institutions at point (or points) A, institutions which at a later point B set the rules of the political game between the same or other actors. In retrospect, the historical development can be perceived as an ongoing and self-reinforcing chain of games between actors, institutional change, new games, new institutions, etc. This means that process tracing can be seen as an attempt to reconstruct as closely as possible the chain of social mechanisms which leads from the situation at point $A$ to the situation at point $B$.

What is a social mechanism more precisely? In a recent review article Gerring lists nine distinct meanings of the term (Gerring 2007). In an earlier article Mahoney discovered as many as 24 different definitions of what causal or social mechanism is (Mahoney 2001, table 1). So there is a large variety of definitions but nevertheless one can distinguish a core of assumptions concerning all uses of the term. First, mechanisms are regular patterns of specific kinds of actions and interactions, possibly also of social relations. Secondly, mechanisms are causally productive: they bring about the outcomes that we are interested in. Therefore, demonstrating the social mechanism at work will also provide an explanation of how a certain state of affairs came to be as it is. Thirdly, the idea of mechanisms implies the possibility that the pattern discovered in one context can be discovered in others. They are portable, as Falleti and Lynch put it $(2009,19)$. There is no point in talking about mechanisms if what is discovered is a singular trajectory of events producing other events without any generalisable element. However, in our interpretation, accounts of social mechanisms are not general theories

\footnotetext{
${ }^{4}$ The functional mechanism is less relevant in an intentional perspective (see Elster 1989, 99-100 for a general criticism of functional explanations in social science).
} 
for the reason that while they are somewhat general they are not universally general in the way general theories are supposed to be. A theory is universal when the conditions of its application can be defined. This is not possible in the case of social mechanisms.

We will develop our understanding of social mechanisms via the work of Jon Elster. Elster does not specifically speak of social mechanisms, as a number of mechanisms he is interested in, are rather psychological than social ones. Elster 'defines' mechanisms as follows: 'Roughly speaking, mechanisms are frequently occurring and easily recognisable causal patterns that are triggered under generally unknown conditions or with indeterminate consequences' (Elster 2007, 36; emphasis in original). The latter part of the definition is important. We do not know in advance the general conditions in which mechanisms are triggered, nor can we tell in advance the consequences of their working. This means that the social mechanisms that social scientific research has discovered - from relative deprivation to the tragedy of the commons - provide the social scientist with a tool box to be used when approaching empirical research questions. We do not know in advance which tool to pick up but we will discover it when getting accustomed to the work at hand.

Elster's definition above does not entail that accounts of mechanisms should be constructed by reference to actors' intentions and actions. However, Elster and other like-minded 'analytic sociologists' link actor-centred approaches and mechanism thinking together (see e.g. Hedström 2008). That is also what we want to do. We understand social mechanisms as consisting of bundles of actions and interactions between actors. These actions are rational in a 'thin' sense. Individual actors are assumed to have some logical consistency in the pursuit of their goals, whereas the nature of those goals (the preferences of the actors, including the social norms they adhere to) is not assumed a priori but open to empirical investigation - where the social and institutional context is of crucial importance (cf. Elster 1983). ${ }^{5}$ In this perspective social mechanisms are intentionally based patterns of action and interaction (cf. Hedström and Swedberg 1998; Elster 2007). ${ }^{6}$ Such mechanisms can be used ex post to interpret a specific chain of events, and we can predict that they may occur in other similar contexts with a similar, thinly rational, constellation of actors. But we cannot predict it with certainty, nor with some, more or less precise, probability.

The logic of generalisation here is based on Weberian ideal types, which are theoretical models that accentuate certain 'rational' characteristics of a given social phenomenon. Ideal types are abstract simplifications and do not claim to be true in an absolute empirical sense, but if adequately constructed they can be fruitful in interpreting the logic of social interaction in a certain specific context. One way of describing this form

\footnotetext{
${ }^{5}$ Falleti and Lynch $(2009,6-7)$ see rational choice as one mechanism among others. In our Elsterinspired perspective some type of (thin) rationality is an element virtually in all social mechanisms - and that is what makes them portable. In his discussion of 'situation analysis' Karl Popper sees 'the rationality principle' - the assumption that persons and agents act appropriately in accordance with the situation - as an integral part of every, or nearly every, testable social theory (Popper ([1967] 1985).

${ }^{6}$ Hedström and Swedberg's examples of mechanisms are all thinly rationalistic: Merton's idea of selffulfilling prophecy (e.g. a run on a bank), Coleman's idea of network diffusion (e.g. of a new medical drug), and Granovetter's idea of threshold-based participation in collective behaviour (cf. Hedström and Swedberg, 1998). (These mechanisms are obviously less protracted than the efficiency, legitimacy and power mechanisms of path dependence.) Gerring discusses Elster's and Hedström and Swedberg's understanding of mechanisms as one of his nine meanings but he seems to overlook the central role of intentionality and thin rationality in their conceptions (Gerring 2007).
} 
of generalisation is that identifying a certain mechanism in one context generates reasonable expectations to finding a similar mechanism in another similar setting (Hertting 2003; cf. also Somerville and Bengtsson 2002). ${ }^{7}$

This 'thin generalisation' based on ideal types can be contrasted to the alternatives suggested in the literature. Several author's see a 'causal' mechanism simply as an intervening variable (e.g. King, Keohane and Verba 1994) or a chain of variables (e.g. Chandra 2006), which raises the question of how to 'control for' the endless number of relevant variables in an historical study on the macro level. Other authors, like Falleti and Lynch (and Mahoney discussing path dependence), try to achieve generalisability by seeing mechanisms as deterministic, which gives rise to the problems discussed above.

To sum up the discussion about process tracing and path dependence: Three central elements of actor-based path dependence analysis are (1) the event or events at point or points A, where one historical path is 'chosen' instead of another (the 'critical juncture'); (2) the decision-making process at point B, where the effects of the choice at point A become visible (the 'focal point'); and (3) the mechanism or mechanisms that explain the effects of the event at point $\mathrm{A}$ on the decision-making situation at point $\mathrm{B}$. The logical way to identify these elements is to 'write history backwards' starting at point $\mathrm{B}$, which would typically be an important and visible political decision-making process. If we find that some, otherwise plausible, alternatives were not chosen or even considered at that point, this would be an indication of where to find the previous point or points A. Comparing the situations at these two points should then give a clue to what type of actor-based mechanism has been at work between the two events.

Counterfactual analysis is an implicit element in a perspective of path dependence. What alternative development would have been possible at point $\mathrm{B}$, if the event at point A had not occurred? The Nordic project included counterfactual analysis on two different levels. First, the individual links in the historical chains - the decision-making processes - were analysed making use of records of the political discourse and interaction in order to identify discarded alternatives. When and why were alternative policies left aside, that might have lead to a development closer to the housing regimes of the other countries? Did these alternatives at some point of time enter the political agenda or were they even perceived of? Second, the counterfactual analysis of the overall development of the housing regime in one country was carried out by using the development in the other countries as contrasting relief. Why were the housing institutions in country A different from those in country B? Why did some particular form of tenure become important in country A while it barely existed in country B? Such counterfactual questions are often posed in comparative research, but they are seldom used as an explicit method of comparison.

\section{Comparing path dependence - contexts and periodisation}

In their paper on the use of mechanisms thinking in social and political analysis Falleti and Lynch stress the importance of context in explanations that operate with the concept

\footnotetext{
${ }^{7}$ Goldstein comes close to this when stating that process tracing consists of 'analyzing a case into a sequence of events and showing how these events are plausibly linked given the interests and situations faced by groups or individual actors' (Goldstein 2003, 47).
} 
of mechanism (Falleti and Lynch 2009). An empirically-backed account of the operation of a social mechanism in itself does not provide the full explanation of the phenomenon at hand. Mechanisms operate in social, political and cultural contexts, and what the outcome of their operation turns out to be depends quite a lot of the relevant context. This is one reason why outcomes of the operation of mechanisms cannot be specified in advance. As the authors put it: 'mechanisms must be general enough to be portable across different contexts but may produce different results in analytically nonequivalent contexts' (Falleti and Lynch 2009, 3).

However, it is not absolutely clear how this portability is achieved. They explicitly disagree with Mahoney's notion about mechanisms being deterministic in their operations. At the same time they refer the indeterminacy to differences between contexts where mechanisms operate, which means that the same mechanism can lead to different outcomes in different settings (Falleti and Lynch 2009, 5). This seems to imply that if mechanisms are detached from outcomes they would still have deterministic properties - and Falleti and Lynch end up rather close to Mahoney's position after all. (Below we propose an alternative logic to make mechanisms portable without falling back to determinism - by assuming thin rationality.)

What the relevant context is, depends on the question studied, as well as the perspective from which it is studied. Accounting for the context is like map-making. Many different kinds of maps can be drawn of the same environment, some very detailed, others rather summary, some including the topography, others ignoring it, etc. The environment of any phenomenon includes such a large variety of different aspects that it is impossible to account for in its entirety. One has to focus on what is relevant and important for the question at hand. Therefore accounting for the relevant context is both problem driven and theory-dependent.

Accounting for the context is problem driven simply in the sense that for the topic we study some aspects of the environment are more important than others. Let's take an example from our study. In Finland one important critical juncture in housing policies was the reconstruction period after the Second World War. One of the reforms that paved way for future housing policies was the establishment of a state housing finance system called Arava. It is obvious that the severe housing shortage at the time, as well as the shortage of capital, the depression of housing production and the birth of 'babyboomers' were crucial contextual factors for the establishment of Arava - rather than some other reconstruction period phenomena, like the 'dance craze' that followed lifting the war-time ban on popular entertainment. The theoretical element in the example has to do with our actor-based analysis: as the context for the 'game for Arava', the political actors' electorate and interest-base, and their ideological orientations, as well as the general political and ideological power relations were mapped. These are the contexts that our thinly rational actors themselves take into account when deciding between alternative courses of action. Generally, determining the context in our research was empirically open in the sense that there was no theoretical master frame that would have specified in advance the contexts to be taken into account. Such a frame would be a stronger theory than would be feasible in a mechanism based approach (see e.g. Elster 2007).

Falleti and Lynch stress that one of the most important contexts is the temporal one, and particularly one specific aspect of that context. Students operating with the idea of path 
dependence are specifically interested in beginnings: when and how things start (Falleti and Lynch 2001, 12). This is, of course, evident as the idea is to trace the way how the 'weight of history' influences the subsequent course of events. The core assumption of the approach is that history indeed matters. To determine when an institution or process started is not always easy. Most experts think that the welfare state development in Finland only took off after the Second World War. However, some argue that the seeds of the welfare state were sown in the policies initiated during the war. Determining the starting point is just as problem-driven and theory-dependent as specifying the relevant contexts.

Contexts also change over time. For Falleti and Lynch the challenge of an analysis of a historical trajectory is to slice up the temporal context into homogenous subunits (see Falleti and Lynch 2009, 12-17): a certain context begins at one point of time and ends at another, just to develop into another context that will eventually end and become a third context etc. To Falleti and Lynch periodisation is just the method to do this slicing up of the context.

Periodisation needs a clear rationale to be really useful in research, and it has to be based on the problem and the perspective of the study. And it can enter the research process in different points and function in different ways. Dividing the development of the phenomenon studied in periods is sometimes a research result. Falleti and Lynch, however, discuss periodisation as a device for the temporal organisation of the context in which the development studied happened. This is also how periodisation was used in our research - although we did not see the periods à priori as different contexts but rather the different countries with their respective housing regimes ${ }^{8}$

In our case there was also an additional theoretical element that Falleti and Lynch do not discuss. The idea was that the development of housing policies can be divided in four phases. In the establishment or introduction period housing becomes a political question, housing institutions are introduced and established as well as political interventions in the housing market. However, in this phase there is no significant public support for housing production. After the establishment phase comes the construction period in which the main concern of housing policy is to build the housing shortage away, that is, to boost housing production as much as possible. This is a time for construction also in another sense: the systems of policy and provision that come to set their mark to the subsequent development are constructed in this phase. With increasing housing construction comes inevitably a time when the housing shortage is over. This initiates the management period in which producing as much as possible is not the main concern any more. The focus of housing policy shifts to the management, maintenance and renewal of the housing stock created. In this phase politics of housing becomes politics of residence where questions of social segregation, environmental sustainability, tenant participation as well as other issues concerning housing quality grow more central. Typically the housing estates built during the construction period now becomes the target of increasing criticism. In the last phase, the retrenchment or privatisation period, the housing policies and institutions developed in the previous periods are questioned, critically evaluated, and sometimes modified, sometimes

\footnotetext{
${ }^{8}$ Defining historical periods as different contexts is somewhat related to the bold suggestion by King, Keohane and Verba (1994) to look upon different time periods as different cases in comparative case study research. In both instances one risks overlooking, or at least underestimating, the independent impact of the time dimension - almost as if denying that history matters.
} 
abolished. In this phase the state starts to withdraw from its previous role as one of the central actors in the housing provision. ${ }^{9}$

This periodisation was used in our research in a way that resembles Max Weber's historical ideal types. In Weber's well-known study of the Medieval western city (see Weber [1922], chap. VIII) he constructs an ideal type of the western city by putting together various observed general characteristics of European cities. The construct he produces is a pure type in the sense that no one historical city fully conforms to the ideal type. The usefulness of the construct is that it provides hypotheses about the similarities and differences between the various city cultures that Weber discusses in his study.

Now a crucial difference between Weber's ideal type and our periodisation is that while the former is more or less a device for comparison and categorisation of different cities without a clear rationale, the latter is a model of the process of policy change, and it has a clear, reasonable rationale, like several other of Weber's ideal types. The sequence of periods from establishment to management can be explained by the inherent dynamics of systems of housing provision. In the book we ask whether the transition to the last, retrenchment phase can also be integrated in the same evolutionary logic or whether it should to a larger degree than the previous ones be interpreted as a result of ideological influences.

The periodisation was used as an ideal type in the sense that it was a model that each one of us five researchers tried to 'fit' in the histories of our own national housing policies. We wanted to find out whether such periods could be distinguished in the respective countries and whether they followed the evolutionary trajectory our ideal type suggested. We were also interested in dating the beginnings and endings of each period. We actually found that the periodisation and its model of policy change worked reasonably well in all cases. The timing of the periods was somewhat different in the different countries, sometimes the boundaries between periods were hard to distinguish, and in the Finnish case the management and retrenchment periods were overlapping. In our experience the periodisation forced us to think more systematically about the housing histories of the five Nordic countries. This rather simple periodisation might very well be applicable more generally to analysing the development of housing policies in Europe and elsewhere in the industrialised world. ${ }^{10}$

\section{Concluding discussion}

This paper has tried to describe and discuss several methodological aspects of our comparative historical research on Nordic housing policies. The project was methodologically informed from the start, discussing institutionalism, process tracing and periodisation extensively. Nevertheless, to a large extent this paper is the result of post-project reflections on our research experience in relation to recently published work on path dependence, social mechanisms and contextualisation. This also means that many aspects of the approach still need to be clarified and specified. Nevertheless,

\footnotetext{
${ }^{9}$ We used a periodisation of the development of housing policy originally proposed by Jensen in studying Danish housing policy (Jensen 1995). The periodisation was discussed in our team and subsequently reworked for the purposes of our research.

${ }^{10}$ The periodisation has been used in at least one other research apart from the studies by our team members (see Holt-Jensen and Pollock 2008).
} 
we obviously see our form of comparative process tracing as a fruitful way to pursue comparative housing research, especially the kind that takes history seriously.

In our research the focus was on housing policies and especially policies concerning housing tenure. We see no obstacle to using the kind of process tracing here advocated in analysing other housing institutions and issues. What was distinctive in our approach was moving from more general accounts of the development of housing policies to more intensive studies on specific critical junctures or focal points. The actor-centred element of our research was most prominent in the intensive studies of decision making processes. Most importantly, the approach presented is portable to other research topics. We claim that the ideas about weak path dependence, critical junctures and focal points, contextual rational action, social mechanisms, contexts and periodisation are all applicable to other kinds of institutional and political change - and lack of change. And certainly not only in housing.

The idea of path dependence of housing policies and institutions was very central to our research. Regardless of whether path dependence is seen as a theory or a perspective on societal processes, some idea of path dependence seems to be an inevitable element of comparative process tracing. In the very loose sense of 'history matters' everything that is chronological is probably also path dependent, so the idea cannot be avoided, if one wants to analyse processes of change and stability.

However, as argued above, 'history matters' has to be combined with an account of how it matters, and our account was action-centred and made use of the idea of social mechanisms. There is, however, no overarching reason why process tracing should necessarily adopt these concepts and ideas. It can very well approach its topic armed with a theory of action that is completely different from the one advocated here. For example, much of historical social science is now inspired by Foucauldian ideas that are radically different from our approach. What is similar between Foucauldians and us is the interest in detailed analysis of strategic points of change. We conceptualise them as actions and interactions between intentional actors, Foucauldians would rather see them as ruptures in discursive fields concerning some object of power and knowledge. What a Foucauldian analysis of the development of the discursive field of Nordic housing policies would look like is hard to imagine but it certainly could use an approach that resembles comparative process tracing.

As mentioned the line between theory and methodology is not always clear-cut in qualitative research. And some of the methodological lessons from our approach could also be seen as theoretical. So how should we move forward - methodologically and theoretically - from what we have found out? Analysing the processes in terms of the three - admittedly very general - mechanisms of efficiency, legitimacy and power made it possible for us to understand the basis of institutionalisation, and also the nature of the driving forces behind institutional change, as well as the obstacles against it. The analysis of the Nordic housing histories teaches us that the three mechanisms often work together and that it is not always easy to point out one of them as decisive.

This is partly an expression of the very long historical perspective of our project (about 100 years). First of all, this means that far from all events and mechanisms can be traced in detail. Second there are data problems, at least with the earlier stages of the period. For example interviews are not possible and survey data are not available. To a large 
extent we had to reconstruct the mechanisms from official records of the public debate and decision-making. ${ }^{11}$ Nevertheless, exploring further the relation between the mechanisms should be a fruitful way towards developing the theory of path dependence both in housing and more generally. One way to do that would be to get closer to the actors and their interaction. Especially this could be done for the recent years, more than we had resources for in the Nordic project. This would probably reveal that the widely defined mechanisms of efficiency, legitimacy and power really consist of a number of different variations and combinations.

When it comes to the three Lukesian 'faces' of path dependence the development over time was interesting. During the establishment phase, with its relatively ad-hoc policy decisions and institutions, alternative solutions were often discussed explicitly. To some extent this was still done in the 'formative' decision-making after World War II, even though fewer alternatives were now conceived as feasible. When we move further into the construction phase, the form of path dependence changes from favouring one alternative over another towards limiting the political agenda or even narrowing perceptions of what is feasible. This continues into the management phase, and even in the retrenchment phase, when Swedish and Danish non-socialist governments go for 'system shifts', their proposals lean heavily on the existing institutions - and regardless of this they still meet with dogged resistance.

This pattern implies that decision-making, agenda-setting and perceptual path dependence may be used to construct a theoretical ladder or scale of institutionalisation, with 'not perceived' as the lowest level, via 'not on the agenda', 'on the agenda but decided against', 'on the agenda and decided in favour of', 'one and only alternative on the agenda' up to 'one and only alternative perceived'. The application of such a ladder should also be a fruitful contribution to theory development in the academic discourse of path dependence.

\section{References}

Abbott, A. (2001) Time matters. On theory and method. Chicago and London: University of Chicago Press.

Annaniassen, E. (2008) Path dependency and counterfactual analysis. The exchange of historical experiences in Norwegian and Swedish housing policy'. Paper presented at the ENHR International Research Conference 'Shrinking Cities, Sprawling Suburbs, Changing Countrysides', Dublin, July 2008.

Arnott, R. (1987) Economic theory and housing. In: E. S. Mills (ed.) Handbook of Regional and Urban Economics, Vol. II. Urban Economics. Amsterdam: North-Holland, pp. 959-988.

Bengtsson, B. (2001) Housing as a social right: implications for welfare state theory. Scandinavian Political Studies, 24(4): 255-275.

Bengtsson, B. (2004) Swedish housing corporatism - a case of path dependency?. Paper presented at the ENHR International Research Conference 'Housing: Growth and Regeneration', Cambridge, July 2004.

Bengtsson, B. (2008) Why so different? Housing regimes and path dependence in five Nordic countries. Paper presented at the ENHR International Research Conference 'Shrinking Cities, Sprawling Suburbs, Changing Countrysides', Dublin, July 2008.

Bengtsson, B. (2009) Applying path dependence perspectives in housing studies - review and discussion. Paper presented at the ENHR International Research Conference 'Changing Housing Markets: Integration and Segmentation', Prague, June 2009.

\footnotetext{
${ }^{11}$ Another complication is that it is not always easy to distinguish between legitimacy and Lukes' third face of perceptual power.
} 
Bengtsson, B. (ed.), E. Annaniassen, L. Jensen, H. Ruonavaara and J. R. Sveinsson (2006) Varför så olika? Nordisk bostadspolitik i jämförande historiskt ljus [Why so different? Nordic housing policy in comparative historical light]. Malmö: Égalité.

Bengtsson, B. and H. Ruonavaara (2010) Introduction to the special issue: path dependence in housing. Housing, Theory and Society 2010, iFirst article.

Chandra, K. ( 2006) Mechanisms vs. Outcomes. Qualitative Methods 4(1): 6-13.

Collier, R.B. and D. Collier (1991) Shaping the political arena. Critical junctures, the labor movement, and regime dynamics in Latin America. Princeton: Princeton University Press.

David, P. A. (1985) Clio and the economics of QWERTY. American Economic Review 75(2): 332-337.

David, P. A. (2007) Path dependence, its critics and the quest for historical economics. In: G. M. Hodgson (ed.) The evolution of economic institutions. A critical reader. Cheltenham: Edward Elgar, pp. 120-142.

Dynarski, M. (1986) Residential attachment and housing demand. Urban Studies 23(1): 11-20.

Elster, J. (1983) Sour grapes. Studies in the subversion of rationality. Cambridge: Cambridge University Press.

Elster, J. (1989) Nuts and Bolts for the Social Sciences. Cambridge: Cambridge University Press.

Elster, J. (2007) Explaining social behavior. More nuts and bolts for the social sciences. Cambridge: Cambridge University Press.

Falleti, T. G. and J. F. Lynch (2009) Context and causal mechanisms in political analysis. Comparative Political Studies 42(9): 1143-1166.

George, A. L. (1979) Case studies and theory development: The method of structured, focused comparison. In: P.G. Lauren (ed.) Diplomacy: new approaches in history, theory and policy. New York: The Free Press, pp. 43-68.

George, A. L. And T. J McKeown (1985) Case studies and theories of organizational decision making. In: L. Sproull and V. Larkey (eds) Advances in information processing in organizations, Vol. 2. Santa Barbara: JAI Press, pp. 21-58.

Gerring, J. (2007) The mechanismic worldview. Thinking inside the box. British Journal of Political Science 38(1): 161-179.

Goldstone, J. A. (2003) Comparative historical analysis and knowledge accumulation in the study of revolutions. In: J. Mahoney and D. Rueschemeyer (eds) Comparative historical analysis in the social sciences. Cambridge: Cambridge University Press, pp. 41-90.

Hall, P. A. and R. C. R. Taylor (1996) Political science and the three new institutionalisms. Political Studies 44(5): 936-957.

Hedström, P. and R. Swedberg (1998) Social mechanisms: an introductory essay. In: P. Hedström and R. Swedberg (eds) Social mechanisms. An analytical approach to social theory. Cambridge: Cambridge University Press, pp. 1-31.

Hedström, P. (2008) Studying mechanisms to strengthen causal inferences in quantitative research. In J. M. Box-Steffensmeier, H. E. Brady and D. Collier (eds) The Oxford handbook of political methodology. Oxford: Oxford University Press.

Hertting, N. (2003) Samverkan på spel: rationalitet och frustration i nätverksstyrning och svensk stadsdelsförnyelse [Games local actors play: rationality and frustration in network governance and Swedish neighbourhood renewal]. Stockholm: Égalité.

Holt-Jensen, A. and E. Pollock (eds.) (2008) Urban sustainability and governance. New challenges in Nordic-Baltic housing policies. New York: Nova.

Hughes, T. P. (1983) Networks of power. Electrification of the Western society 1880-1930. Baltimore: John Hopkins University Press.

Jensen, L. (1995) Udviklingstræk ved det almennyttige beboerdemokrati i Danmark 1900-1990 [Trends in resident democracy in Danish social housing]. In: M. Madsen, H.-J. Nielsen and G. Sjöblom (eds) Demokratiets mangfoldighed: tendenser i dansk politik [The pluralism of democracy: trends in Danish politics]. Copenhagen: Forlaget Politiske Studier pp. 225-255.

Kemeny, J. and S. Lowe (1998) Schools of comparative housing research: from convergence to divergence. Housing Studies 13(2): 161-176.

King, G., R. O. Keohane and S. Verba (1994) Designing social inquiry. Scientific inference in qualitative research. Princeton: Princeton University Press.

Lukes, S. ([1974] 2005) Power. A radical view. Houndmills, Basingstoke: Palgrave MacMillan

Mahoney, J. (2000) Path dependence in historical sociology, Theory and Society, 29(4), pp. 507-548.

Mahoney, J. (2001) Beyond correlational analysis: recent innovations in theory and method. Sociological Forum 16(3): 575-593.

Malpass, P. (2000) Housing associations and housing policy. Basingstoke: Palgrave MacMillan. 
Malpass, P. (2005) Housing and the welfare state. The development of housing policy in Britain. Basingstoke: Palgrave MacMillan.

North, D. C. (1990) Institutions, institutional change and economic performance. New York: Cambridge University Press.

Pierson, P. (2000) Increasing returns, path dependence and the study of politics. American Political Science Review 94(2): 251-267.

Pierson, P. (2004) Politics in time. History, institutions and social analysis. Princeton: Princeton University Press.

Popper, K. ([1967] 1985. The rationality principle. In: D. Miller (ed.) Popper selections. Princeton: Princeton University Press.

Putnam, R. D. (1993) Making democracy work. Civic traditions in modern Italy. Princeton: Princeton University Press.

Robertson, D., I. McIntosh and J. Smyth. (2010) Neighbourhood identity: the path dependency of class and place. Housing, Theory and Society 2010, iFirst article.

Rothstein, B. (1998) Just institutions matter. The moral and political logic of the universal welfare state. Cambridge: Cambridge University Press.

Ruonavaara, H. (2005) How divergent housing institutions evolve: a comparison of Swedish tenant co-operatives and Finnish shareholders' housing companies. Housing, Theory and Society 22(4): 213236.

Ruonavaara, H. (2008a) Home ownership and the Nordic housing policies in the 'retrenchment phase', Paper presented at the ENHR Working Group Conference 'Building on Home Ownership: Housing Policies and Social Strategies', Amsterdam, October 2008.

Ruonavaara, H. (2008b) How are housing policies path dependent?, Paper presented at the ENHR International Research Conference 'Shrinking Cities, Sprawling Suburbs, Changing Countrysides', Dublin, July 2008.

Saunders, P. and P. Williams (1988) The constitution of the home: towards a research agenda. Housing Studies 3(2): 81-93.

Schelling, T. C ([1960] 1980) The strategy of conflict. Cambridge, Mass.: Harvard University Press

Sewell, W. H. Jr. (1996) Historical events as transformations of structures: inventing revolution at the Bastille. Theory and Society, 25(6): 841-881.

Sewell, W. H. Jr. (2005) Logics of history. Social theory and social transformation (Chicago and London: Chicago University Press).

Somerville, P. and B. Bengtsson (2002) Constructionism, realism and housing theory. Housing, Theory and Society 19(3-4): 121-136.

Stahl, K. (1985) Microeconomic analysis of housing markets: towards a conceptual framework. In: K. Stahl (ed.) Microeconomic models of housing markets. Berlin and Heidelberg: Springer-Verlag, pp. 126.

Thelen, K. (1999) Historical institutionalism in comparative politics. Annual Review of Political Science, 2(1): 369-404.

Torgersen, U. (1987) Housing: the wobbly pillar of the welfare state. In B. Turner, J. Kemeny and L. J. Lundqvist (eds) Between state and market: housing in the post-industrial era. Scandinavian Housing and Planning Research, Supplement 1, pp. 116-126.

Tsebelis, G. (1990) Nested games. Rational choice in comparative politics. Berkeley: University of California Press.

Vorms, C. (2009) Long term social impact of Franco's housing policy in Spain. Paper presented at the ENHR International Research Conference 'Changing Housing Markets: Integration and Segmentation', Prague, July 2009.

Weber, M. (no date [1922]) Wirtschaft und Gesellschaft. Paderborn: Voltmedia. 